\title{
AR METHODS FOR THE VISUALIZATION OF THE LOST MARBLE “TRIBUNA” IN THE MAIN APSE OF THE CATHEDRAL OF PALERMO
}

\author{
M. Cannella \\ Department of Architecture, University of Palermo, mirco.cannella@unipa.it
}

\section{Commission II}

KEY WORDS: Augmented reality; Persistent Cloud Anchors, Virtual reconstruction; Tribuna Gagini; Laser scanning survey

\begin{abstract}
:
In recent years research works have shown that augmented reality tools can offer effective support for the dissemination of architectural heritage, when integrated into the information data extracted with surveying and representation tools and further data from other sources, e.g., history.

The development and permanent updating of software platforms dedicated to augmented reality, i.e., Apple's ARKit and Google's ARCore, as well as the introduction of new features, offer today affordable support for the development of AR solutions.

Some operational difficulties are due to the rapid and constant evolution of the technologies; the available solutions can be compared to prototypes and the development of user experience effective solutions appears still lacking. The main subject in the construction of AR solutions is still linked to the development of effective methods to properly set up the visualization of 3D models and their interaction with the real scene. The chosen case study for the test of persistent AR solution for the visualization of works of art is the 'Tribuna', i.e., a monumental and sculptural marble apparatus, that decorated the main apse of the Cathedral of Palermo.
\end{abstract}

\section{INTRODUCTION}

The paper reports the outputs of a research work that aims at testing the efficacy of the Augmented reality solutions for the onsite visualization of sculptural and architectural works that have been changed or are lost after modifications or destructions that interested the work itself or the building that hosted the work. The proposed research work aims at testing two different AR solutions that are capable to provide AR multi-user, repeatable and time persistent experiences.

The first tested solution uses the Persistent cloud Anchors technology of Google ARCore; the second one is based on the Area Targets solution available on the AR Vuforia platform.

The paper reports the workflow that led to the construction of the two AR solutions and a comparison of their on-field performances.

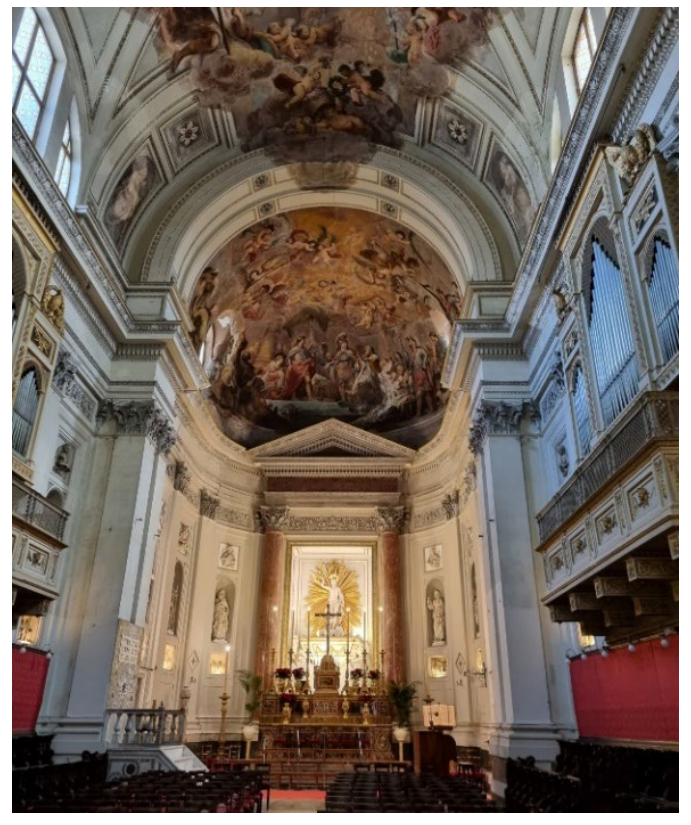

Figure 1. Cathedral of Palermo. Main apse.

\section{RELATED WORKS}

One of most relevant topics proposed by the growing diffusion of AR solutions, especially for the visualization of Cultural Heritage virtual reconstructions, is the demand for time persistent solutions (Guo et al., 2019).

The most effective AR platforms use the SLAM (Simultaneous Visual Location and Mapping) technology to estimate the pose of the device's camera (Carmignani, et al. 2011; Voinea, et al., 2019).

The technology assumes the initial position of the device as the reference for the calculation of the interaction between the virtual objects and the real scene. When a new AR session is launched, the position is once again referred to the initial location of the device. The initial position is not a good reference since it changes at each session; the visualization of cultural heritage works demands a stable and persistent reference linked to the scene and not to the position of the device inside the real environment.

This is why the efforts of scholars and researchers are addressed to the development of time persistent AR solutions (Barrile et al., 2019, Palma et al., 2019; Kaimaris et al., 2021; Torresani et al., 2021); in Morar et al. (2021) have proposed a persistent solution inside the project CultReal; in Bachras et al. (2019) have developed interesting test on the same subject.

\section{DEVELOPED METHODOLOGY}

The aim of the research is the definition of a modus operandi to create three-dimensional digital contents that uses surveying and modelling techniques, integrated to historic sources, to build virtual reconstructions and propose their visualization on site with AR solutions running on mobile devices.

Augmented Reality is a very effective technology for the visualization of virtual reconstructions of monuments (or parts of them) that have been destroyed or radically transformed.

In most cases the tracking of the device's position is a hard work; in a monumental site the orientation is calculated inside a wide scene, with variable lighting conditions and with people moving around. 


\subsection{The case study}

The case study for the proposed AR application is the recontextualization of the virtual reconstruction of a marble apparatus, named 'Tribuna', that decorated the main apse of the Cathedral of Palermo (Bellafiore, 1999).

The 'Tribuna' was commissioned to Antonello Gagini, the most relevant Reinassance sculptor operating in Sicily in the $16^{\text {th }}$ century; the 'Tribuna', that covered the entire semi-circular space of the main apse, was destroyed at the end of the $18^{\text {th }}$ century after a 'renovation' campaign that led to a radical reshaping of the inner structures of the Cathedral (Di Marzo, 1880).

The project, designed by Ferdinando Fuga, aimed at the modification of the load-bearing elements and walls of the central nave, and at the construction dome at the end of the nave; the demolition of the 'Tribuna' was not a part of Fuga's design, but was later operated by some local architects that considered the apparatus inadequate to the new neo-classical layout of the inner space (Basile, 1926).

The layout of this decorative apparatus has come to us through a couple of drawings dated to the $18^{\text {th }}$ century. The drawings show that the 'Tribuna' featured 40 semi-circular niches arranged on three-level; each niche hosted the statue of a saint and Holy Fathers of the Catholic church.

The drawing shows that the 'Tribuna' was horizontally divided in two by a cornice: the lower part hosted the first level of niches, whereas the highest part hosted the remaining two.

At the centre of the apse, corresponding to the longitudinal axe of the nave, were located two major niches; the lower one hosted a sculptural group referred to Holy Virgin's Assumption; the higher niche hosted the statue of Jesus Christ reborn. The back of this niche was opened and allowed the light inside the church; the opening has been closed but it is still clearly visible on the external front of the apse.

After the demolition of the 'Tribuna' the statues were relocated on the pillars that separate the central nave and the aisles.

Some fragments of the capitals and pilasters that decorated the 'Tribuna' are today exhibited at the Diocesan Museum, close to the Cathedral.

\subsection{Virtual reconstruction}

The virtual reconstruction of the 'Tribuna' has been supported by the laser scanning survey of the present apse and by documentary and graphic sources.

A meaningful source for the reconstruction of the 'Tribuna' is a detailed description published in 1880 by the art historian Gioacchino Di Marzo, which reports the overall dimension and the size of some elements.

The data reported by Di Marzo were used as a reference for the construction of a 1:10 model of the 'Tribuna', carried out in the years from 1998 and 2000 by the students of the Academy of Arts of Palermo under the supervision and direction of Professor Salvatore Rizzuti (Rizzuti, 2007). The model is today exhibited in the Diocesan Museum.

Di Marzo published a drawing that documents the layout of the inner space of the Cathedral before the renovation; the main apse shows the section of the Tribuna and its niches.

Another relevant source for the reconstruction work are two perspective drawings, respectively dated 1701(Sutera, 2013) and 1760 (Schiavo, 1760), that depict the central nave and the main apse decorated for celebrations (funerals, crowning and the like). The comparison between the documentary data and the dimensional data extracted from the point clouds supported the solution of some conflicts and mismatches that affected previous reconstructions.

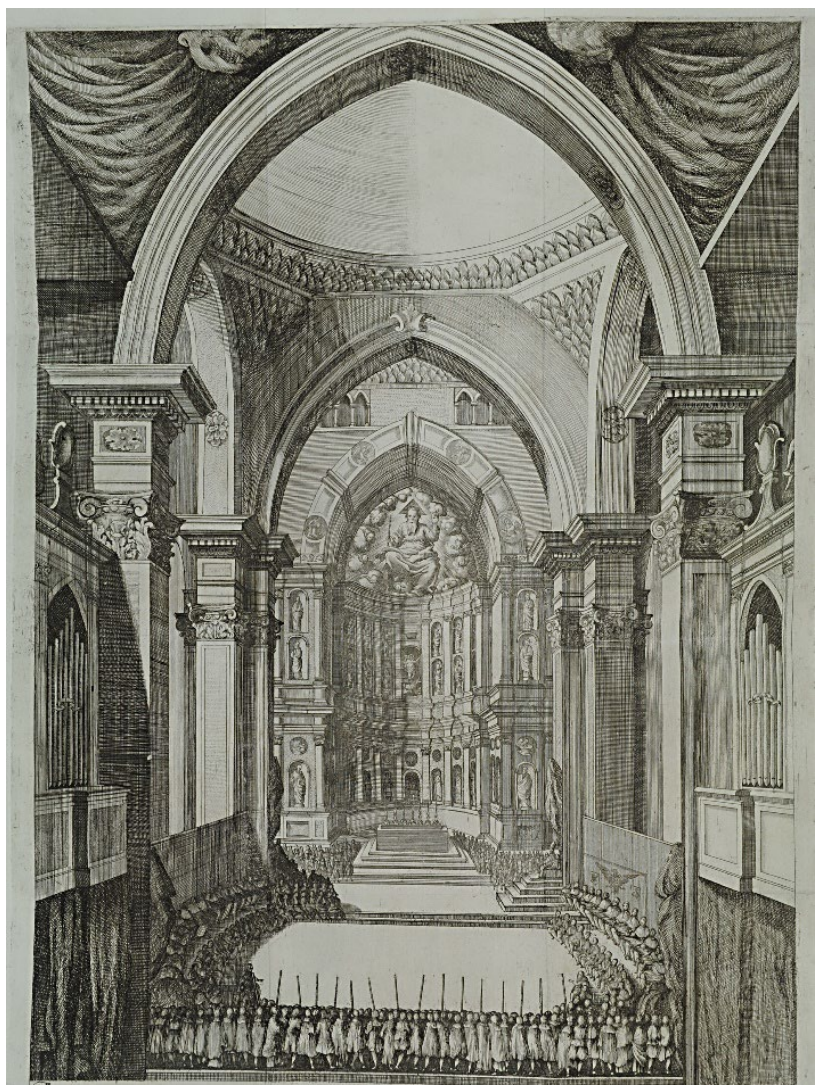

Figure 2. Diego DE LOYA, View of Antonello Gagini's marble Tribuna in the Cathedral of Palermo (1701).

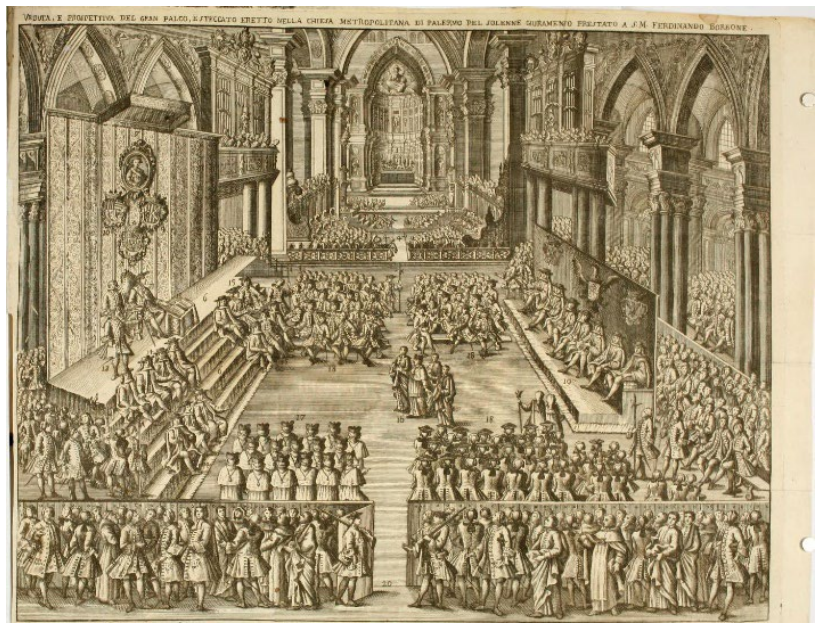

Figure 3. Antonio Bova's view of the nave of the cathedral and the main apse (1760).

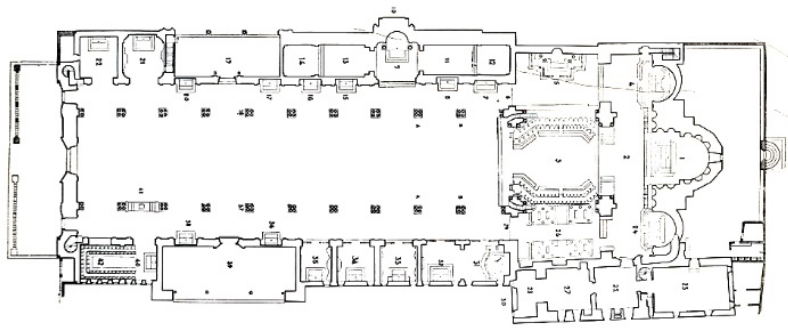

Figure 4. Plan of the Cathedral of Palermo before the 18th renovation (Zanca, 1952). The section of Gagini's 'Tribuna' and its niches appears in the main apse. 
The mesh models of the statues at the sides of the nave were generated from the laser scanning point cloud. Each model was positioned inside a dedicated niche, according to the description provided by Di Marzo.

The models of the capitals and pilasters exhibited at the diocesan Museum have been generated with SfM photogrammetric techniques and scaled with the aid of measures taken with a tape.

\subsection{Augmented reality visualisation}

The first obstacle that the experiment for the AR visualization of the 'Tribuna' had to face is not linked to the technologies used for the purpose, but to the interaction between the reconstruction model and the real scene.

The eastern part of the cathedral has been strongly reshaped during the renovation and the connection between the main and the minor apse has been interrupted, furthermore, the longitudinal depth of the main apse has been extended. The minor apses are hidden by newer apses built along the renovation. The southern minor apse, today connected to the cathedral by a secondary path, is today used as an exhibition hall.

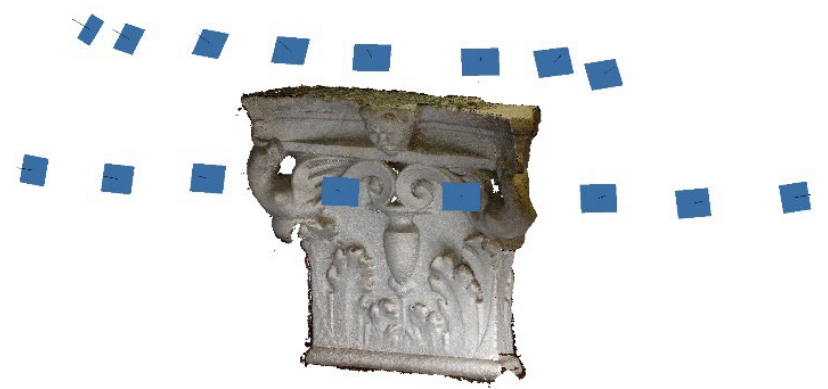

Figure 5. Polygonal model of a capital of the Tribuna, generated with SfM photogrammetric tools.

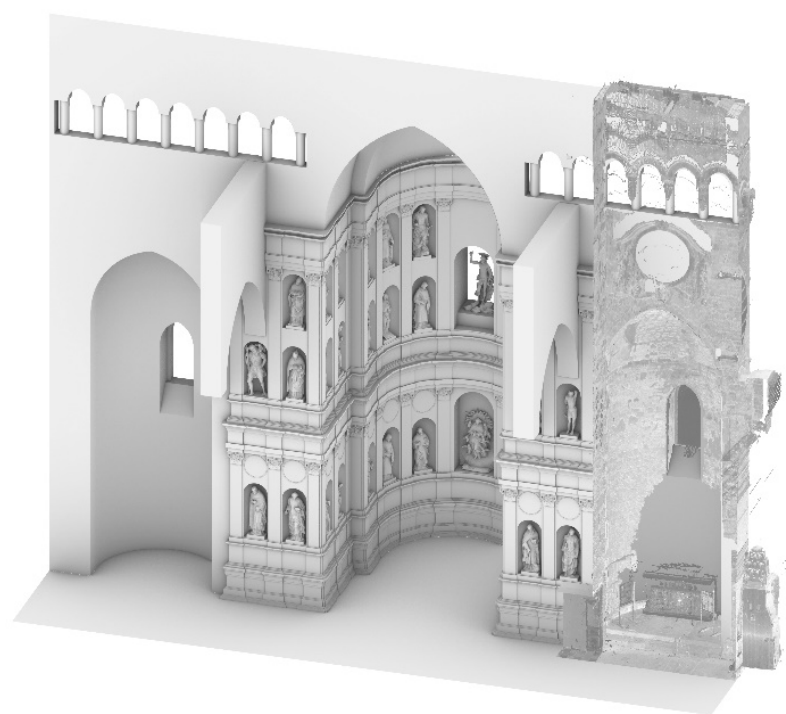

Figure 6. Axonometric view of the reconstruction model of the Tribuna.

The present layout of the Cathedral suggested the development of two AR applications: the first application, that allows the visualization of the reconstruction model from the nave, echoes the $18^{\text {th }}$ century drawings; the second one allows the visualization of the 'Tribuna' from the medieval southern minor apse, through the virtual removal of the wall that separates the apses. This visualization, that proposes a lateral, partial but close view of the 'Tribuna', appears impressive.
The superimposition of the reconstruction model to the present scene had to be adjusted for the visualization from the nave, whereas the model has been visualized in its full extension in the application for the visualization from the medieval southern apse. The original extension of the 'Tribuna' included the walls that separated the main apse from the minor ones. The visualization of these terminal elements from the nave resulted confusing because it hid a great part of the present scene; this is way the ends of the reconstruction models have been trimmed for the visualization from the nave and were kept for the visualization from the ancient minor apse.

The focus of the research, as mentioned above, is the development of a time persistent AR solution for mobile devices. The proposed solution aims at offering the experience of the visualization of the 'Tribuna' at many visitors at the same time; furthermore, the app aims at setting a stable reference for the estimation of the pose of the device's camera, that doesn't need recalculation at each session.

The experiment has tested two different AR solutions: the first one, developed by Google for the platform ARCore, is named Persistent Cloud Anchors; this solution allows to store in a cloud database the data that allow to set up a stable connection between the real scene and the digital 3D models.

ARCore and other similar solutions as Apple ARKit, uses 'anchors' to operate an optimal connection between virtual elements and the real scene.

Anchors link the position of a digital model to the morphology of the real scene and do not use the reference system calculated at the start of the session.

It is well known that these platforms use SLAM algorithms to integrate the video streaming captured by the device's camera with the data on the movement registered by the device's IMU (Inertial Measurement Unit) platform. A relevant feature of these processes is the ability to refine the estimation of the morphology of the scene during the session. The system is therefore capable of improving in real time the accuracy of the calculation of the device's pose; these refinements do not affect the visualization of the $3 \mathrm{D}$ model, because it is permanently linked to a specific area of the scene, corresponding to an anchor.

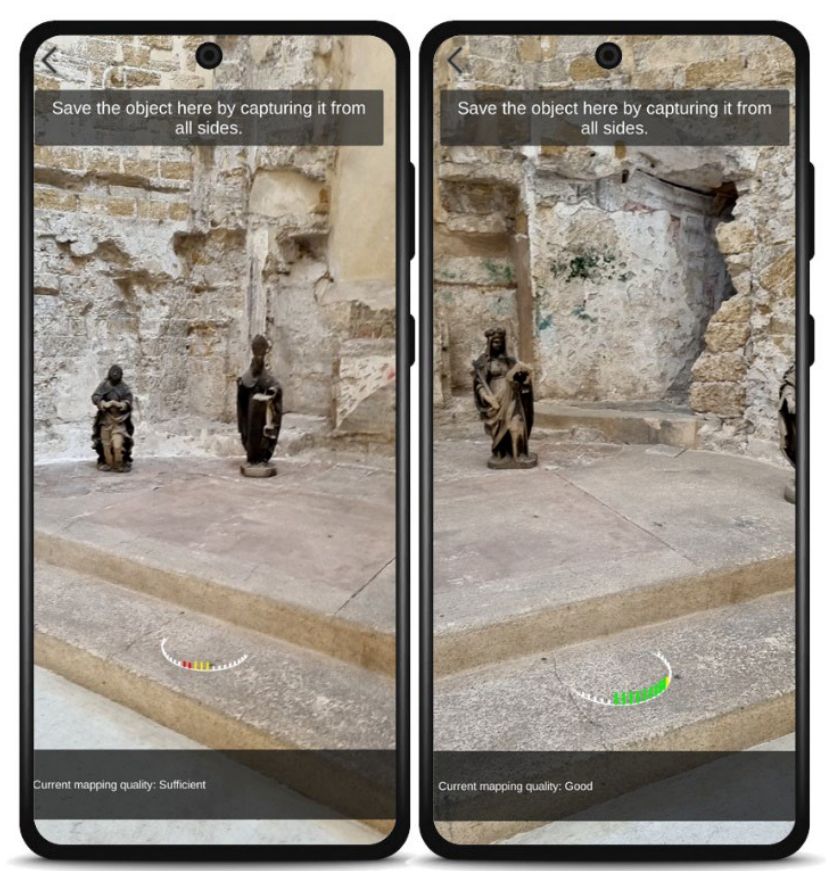

Figure 7. The anchor is positioned and the surrounding area Is surveyed. 


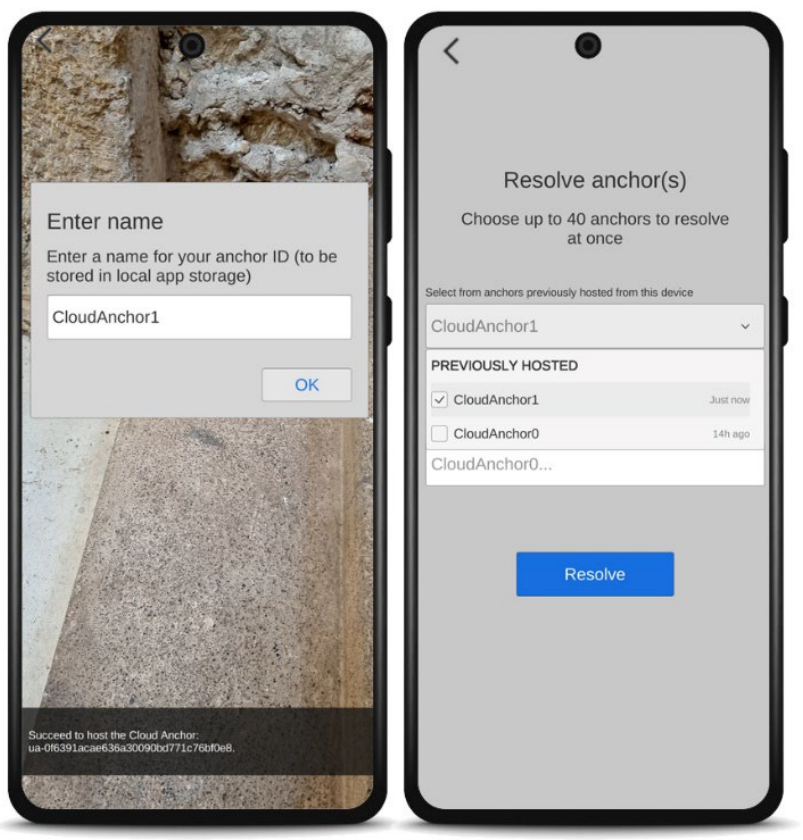

Figure 8. Left: The app used by the AR operator to name the anchor. Right: The app used by the end user to retrieve the anchor.

The Persistent Cloud Anchors Technology allows to store in the cloud the 3D feature maps of the area located around the anchor, and it is therefore capable to separate the calculation of the position of the object from the adjustment of the camera pose (Cannella, 2021).

In the tested experimentation the Persistent Cloud Anchors has been used for the development of two Unity 3D applications: the first one is dedicated to the Hosting of the anchor linked to the 3D reconstruction model of the 'Tribuna'; the second one, addressed to the end users resolves the anchor and allows the visualization of the reconstruction model in its original position, from any point of view.

The first application is used on-site by the AR operator, which links the anchor to a specific, permanent, and visible point of the scene, lying on a flat surface that has been previously surveyed. This point becomes the origin of the reference system of the $3 \mathrm{D}$ reconstruction model.

The anchor's positioning is performed as follows: the AR operator frames the flat area where the reference point is located; once the flat area is identified by the system, the operator taps on the screen to fix the position of the reference point.

At the end of this process the anchor is linked to the reference point.

At this stage, the AR operator moves around to frame the anchor from different points of view; a graph will show in real time the quality of the recorded data needed for the construction of the $3 \mathrm{D}$ feature map of the area around the anchor.

The anchor is finally stored in the Google Cloud Platform and is identified by an ID chosen by the AR operator.

The second application, addressed to the end user, will resolve the anchor, and will display the virtual model in its proper position; once the anchor has been retrieved by its ID, manually or with the aid of a QR code, the user has to frame the anchor's area for few seconds. The system will rapidly resolve the anchor and display the model in the real scene.

From this moment on the system uses motion tracking algorithms to calculate in real time the device's camera pose; the user will be free to move around and watch the 'Tribuna' from any point of view.
This application demands a stream of data from the device to the Google Cloud; this stream doesn't need a fast connection because these data take few bytes, but a connection is needed for the system to work.

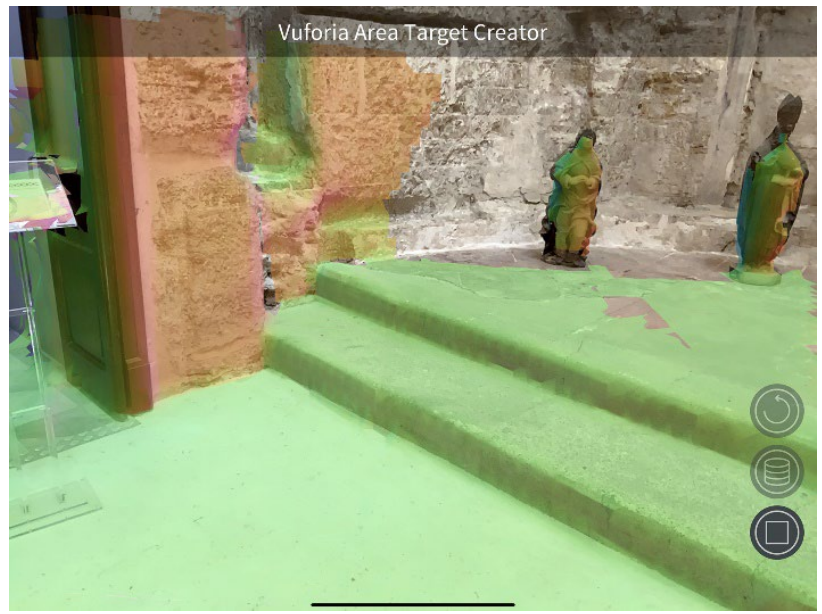

Figure 9. Southern ancient apse: 3D features recording with Vuforia Area Target Creator installed on an iPad Pro equipped with a lidar sensor.

The second AR solution that has been tested is based on the Vuforia Platform; this solution, based on the same technologies discussed so far (ARCore for Android and ARKit for iOS), offers extra interesting tools.

In this research the tool named Area Target has been tested; this tool, similar to Google's Cloud Anchor system, allows the storage the $3 \mathrm{D}$ features of a specific scene and to link these features to a $3 \mathrm{D}$ model.

One advantage of this tool is the capability to store the 3D features in the device; this system works even where an internet connection is not available.

The Area Target technology is based on data that have been recorded with specific scanning systems. At this stage the only compatible systems are the Matterport Pro2 3D camera, some Leica and Navis scanners, the iOS devices equipped with Lidar sensors.

The scanned data are processed and converted by a specific tool named Vuforia Area Target Generator.

This tool uses a 3D scanned model as input and generates an Area Target dataset in Unity and native formats.

Vuforia has developed an app for iOS devices that allows the real time $3 \mathrm{D}$ scanning and generates the data needed for the definition of the Area Target.

In this experiment an iPad Pro has been used to capture the 3D features of two wide areas of the nave at the entrance of the main apse and of the southern ancient apse.

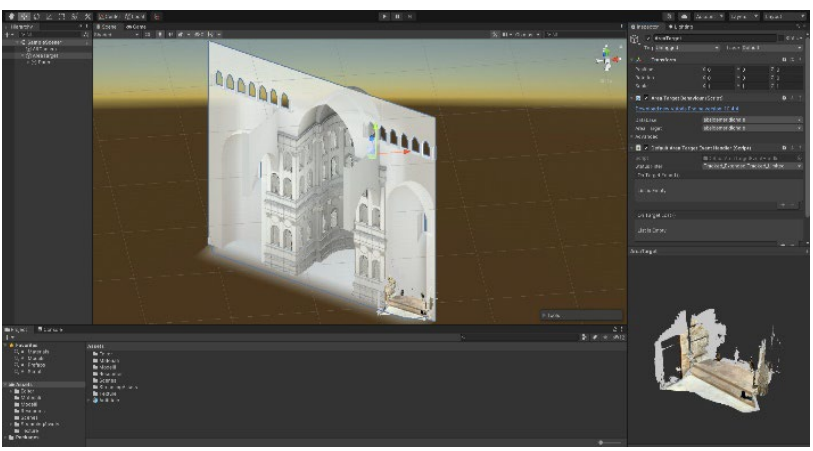

Figure 10. In Unity the 3D reconstruction model is aligned to the 3D data taken with the Area Target tool of Vuforia. 


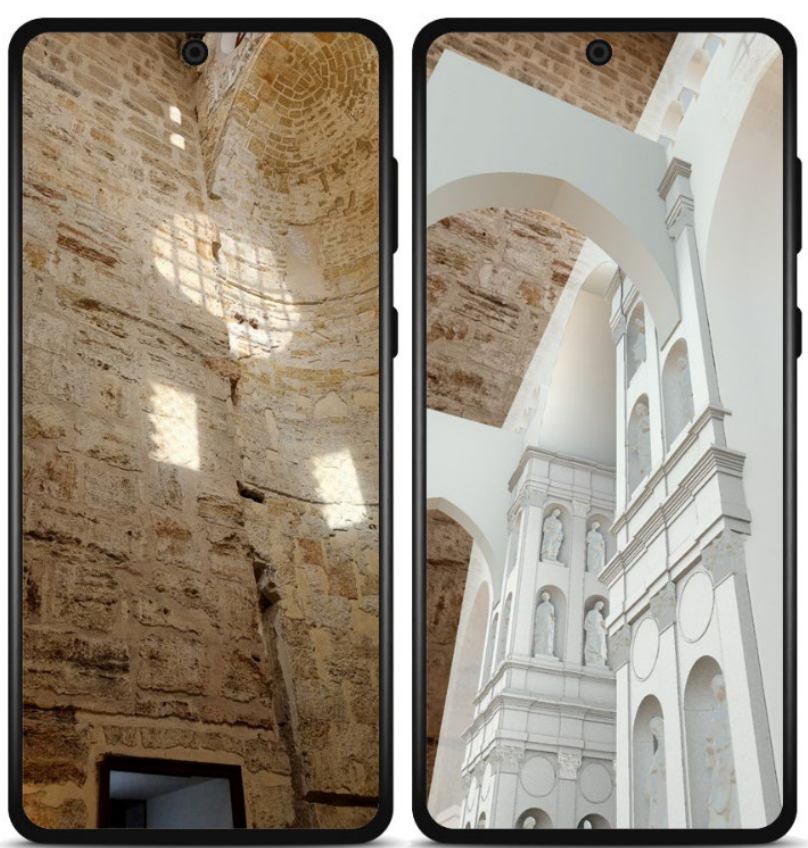

Figure 11. AR visualization of the 'Tribuna' from the southern ancient apse, using the Persistent Cloud Anchors technology of Google ARCore.

The data have been converted in a dedicated dataset and uploaded in the Unity 3D platform. The dataset, linked to Unity's Area Target Game Object, allows the visualization of the 3D features. The AR operator uses Unity to position the virtual 3D model in the captured scene.

When the Unity app is started, the matching between the captured scene and the 3D features stored in the device is fixed in few seconds and the 3D model appears in the position that was previously calculated.

The workflow is really easy to manage: the user frames the captured scene and makes short movements till the matching is solved. At this stage the user can move around in the scene and watch the 3D model from any point of view.

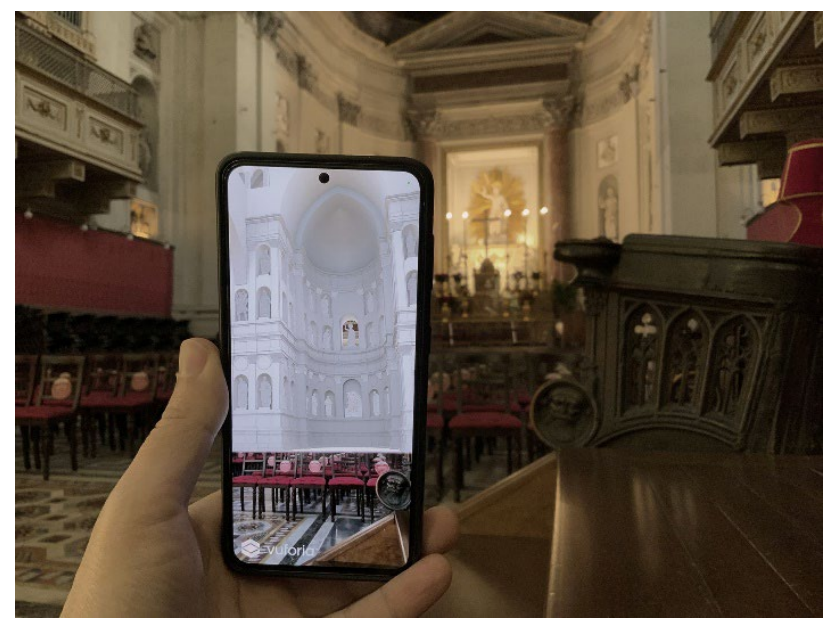

Figure 12. AR Visualization of the Tribuna from the nave of the Cathedral with Vuforia's Area Target tool.

\section{RESULTS}

The first tests developed inside the Cathedral of Palermo show that both ARCOre's persistent cloud anchors and Vuforia's Area
Targets tools provide a stable and robust solution capable of an accurate orientation of digital models in a real scene.

Both technologies solve the initial alignment in few seconds, thus allowing the users to immediately enjoy the visualization.

The tracking systems of both tools, based on the ARCore technology, allow the user to move around up to a distance of almost $8 \mathrm{~m}$ from the anchor.

At this or minor distances the systems provide a good match between real scene and digital model.

This study has not investigated the potentials of the technology developed by Vuforia, especially when surveying data taken with professional laser scanners are available.

\section{CONCLUSIONS}

The research proposes an approach to the definition of AR applications based on time-persistent solutions, using the cloud storage system of anchors and the Area Target technology developed by Vuforia.

Both solutions resulted effective since they offer a visualization experience that can be retrieved and shared by many users at the same time.

The AR visualization of the 'Tribuna' in its original context will offer to visitors the opportunity to understand the meaning and the location of the statues now placed on high pedestals at the sides of the nave and to virtually enjoy the vision of one of the most relevant sculptural works of Sicily.
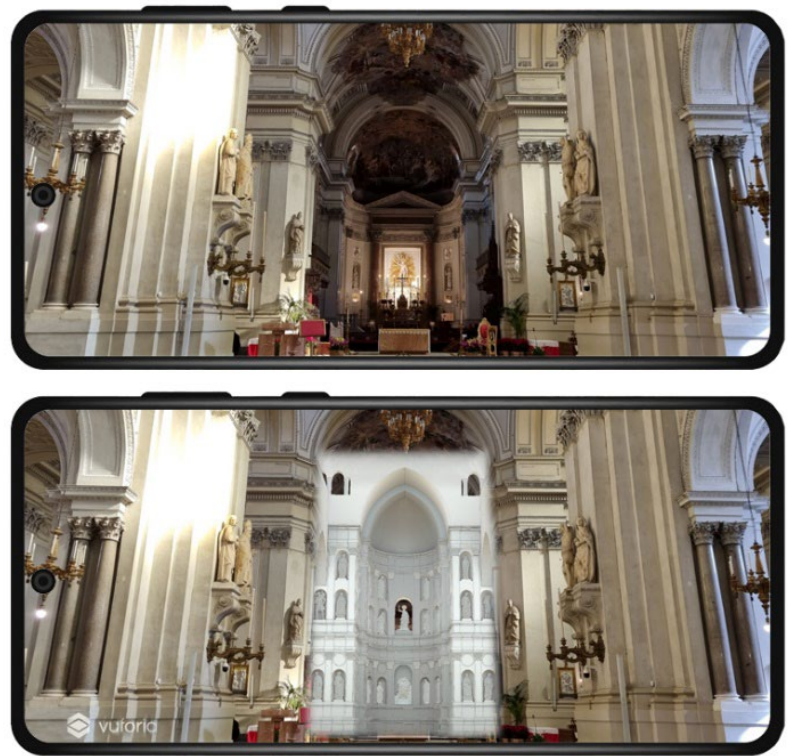

Figure 13. AR visualization of the Tribuna from the nave of the Cathedral with Vuforia's Area Target tool.

\section{ACKNOWLEDGMENT}

The author acknowledges Father Giuseppe Bucaro, Responsible of the Cultural Heritage division of the Diocese of Palermo, Father Filippo Sarullo, Holder of the Cathedral of Palermo and Prof. Pierfrancesco Palazzotto, Responsible of the Diocesan Museum, for having allowed access and data acquisition inside the Cathedral and the Diocesan Museum.

\section{APPENDIX}

The contribution is a product of a research financed by the EU Eurpean Regional Development Fund - PON Aim - Research and Innovation 2014-2020 (Attraction and International Mobility). 


\section{REFERENCES}

Bachras V., Raptis G.E., Avouris N.M., 2019. On the Use of Persistent Spatial Points for Deploying Path Navigation in Augmented Reality: An Evaluation Study. In: Lamas D., Loizides F., Nacke L., Petrie H., Winckler M., Zaphiris P. (eds) Human-Computer Interaction - INTERACT 2019. Lecture Notes in Computer Science, vol 11749. Springer, Cham. https://doi.org/10.1007/978-3-030-29390-1_17

Barrile, V., Fotia, A., Bilotta, G., De Carlo, D., 2019. Integration of geomatics methodologies and creation of a cultural heritage app using augmented reality. Virtual Archaeology Review. 10(20):40-51. https://doi.org/10.4995/var.2019.10361

Basile, N., 1926. La Cattedrale di Palermo: l'opera di Ferdinando Fuga e la verità sulla distruzione della Tribuna di Antonello Gagini, R Bemporad, Firenze.

Bellafiore, G. 1999. La Cattedrale di Palermo, Flaccovio Editore, Palermo.

Cannella, M., 2021. Hulot's Selinunte: digital analysis and virtual reconstruction, SCIRES-IT - SCIentific RESearch and Information Technology Volume 11, Issue 2 (2021). 113-124.

Carmigniani, J., Furht, B., Anisetti, M. Ceravolo, P. Damiani, E. Ivkovic, M., 2011. Augmented reality technologies, systems and applications. Computer Science Multimedia Tools Applications 51, 341-377 https://doi.org/10.1007/s11042-010-0660-6

Di Marzo, G., 1880. I Gagini e la scultura in Sicilia nei secoli XV e XVI, Edizioni librarie siciliane, Palermo.

Guo, A., Canberk, I., Murphy, H., Monroy-Hernández, A., \& Vaish, R., 2019. Blocks: Collaborative and Persistent Augmented Reality Experiences. Proceedings of the ACM on Interactive, Mobile, Wearable and Ubiquitous Technologies 3 (3, Sept 2019), no. $83,1-24$.

Kaimaris, D., Roustanis, T., Klimantakis, K., Karolos, I. A., Patias, P., 2021. Possibilities of spatial correlation of 3d models in an archaeological augmented reality application, International Arch. Photogramm. Remote Sens. Spatial Inf. Sci., XLVI-M-12021, 355-359, https://doi.org/10.5194/isprs-archives-XLVI-M1-2021-355-2021.

Morar, A., Băluțoiu, M., Moldoveanu, A., Moldoveanu, F. and Butean, A., 2021. "CultReal-A Rapid Development Platform for AR Cultural Spaces, with Fused Localization", Sensors 21, no. 19: 6618 .

Palma, V. Spallone, R., Vitali, M., 2019. Augmented Turin Baroque Atria: AR Experiences for Enhancing Cultural Heritage, ISPRS. International archives of the photogrammetry, remote sensing and spatial Information sciences - XLII (W9), 557-564. Rizzuti, S., 2007. La Tribuna di Antonello Gagini nella Cattedrale di Palermo, Palermo.

Rizzuti, S., 2007. La Tribuna di Antonello Gagini nella Cattedrale di Palermo, Palermo.

Schiavo, D. 1760. Descrizione della solenne acclamazione, e del giuramento di fedeltà prestato al re di Sicilia Ferdinando
Borbone composta dal dott. Domenico Schiavo palermitano, Palermo.

Sutera, D., 2013. La rappresentazione della Gloria monarchica attraverso l'effimero nei solenni funerali di Filippo V (1747) e di Carlo III di Borbone (1789) in Sicilia. Soleils Baroques. La gloire de Dieu et des princes en représentation dans l'Europe moderne. Collana di storia dell'Arte $n^{\circ} 17$ Académie de France à Rome Villa Médicis, 469-487.

Torresani, A., Rigon, S., Farella, E. M., Menna F., Remondino, F., 2021. Unveiling large-scale historical contents with V-Slam and markerless mobile AR solutions. International Archives of the Photogrammetry, Remote Sensing and Spatial Information Sciences, Volume XLVI-M-1-2021. 761-768.

Voinea G.D., Girbacia F., Postelnicu C.C., Marto A., 2019. Exploring Cultural Heritage Using Augmented Reality Through Google's Project Tango and ARCore. In VR Technologies in Cultural Heritage, 93(106), Springer International Publishing.

Zanca, A., 1952. La Cattedrale di Palermo (1170-1946), I.R.E.S, Palermo. 